\title{
FOREWORD TO THE ENGLISH EDITION
}

This is basically a translation of the lst German Edition of "Autoradiographie." Mistakes and unclear passages in the original were corrected where found. Some new references have been included to keep the work up to date.

Figures 1, 2, 4, 16, 64, 80,90,91, and 93 are reproduced directly from the German Edition, hence commas are to be seen where periods would normally be in English usage.

The authors and publisher are especially grateful to Professor M. R. F. Ashworth of Saarbrücken for the translation. Our thanks also to Dr. E. Schmatolla of Frankfurt for his help in the final reading of the proofs.

Frankfurt am Main and Berlin, Spring 1971

The authors

Walter de Gruyter \& Co

\section{FOREWORD TO THE GERMAN EDITION}

Up to the end of 1969 , some 10,000. publications had appeared which were concerned with autoradiography: This method has applications in many scientific subjects but, apart from a few summarising treatments*, no inclusive presentation exists so far which can be regarded unequivocally as an introduction to the practical and theoretical fundamentals of this extensive domain.

We planned originally to publish a type of handbook, aimed at giving those interested rapid guidance in the methods and results of autoradiographic investigations. Limitations were, however, imposed on us in this connection. We have had likewise to abandon a complete bibliography to the present monograph. As far as possible, we have cited the newer publications in order to facilitate access to the original literature. We hope that the book will close a noticeable information gap.

We have striven constantly to provide a guide which, firstly, will introduce the fundamentals, methods and problems of autoradiography to the reader who is interested, yet without experience in practical details; and which will, through numerous tips, help him to save time, expense and effort. Secondly, we wanted to give information on those problems which can at present be attacked with greater or lesser success by autoradiographic methods.

\footnotetext{
* See Section 9.2
} 